\title{
Comparision of Response of Oral Versus Injectible Vitamin D in Children Having Rickets
}

\section{Rabia Mazari*}

Department of Consultant Dietitian and Nutritionist, University of Veterinary and Animal Sciences, Lahore, Pakistan

*Corresponding author: Mazari R, Department of Consultant Dietitian and Nutritionist, University of Veterinary and Animal Sciences, Lahore, Pakistan, Tel: +92-42-99211449-50; E-mail: rabia_mazari@yahoo.com

Received date: July 03, 2017; Accepted date: Aug 07, 2017; Published date: Aug 14, 2017

Copyright: (c) 2017 Mazari R. This is an open-access article distributed under the terms of the Creative Commons Attribution License, which permits unrestricted use, distribution, and reproduction in any medium, provided the original author and source are credited.

\begin{abstract}
Malnutrition is one of the major issues around the world. According to one estimation, it is stated that one of three children daily die from malnutrition in all over the world. Rickets is one of the most prevalent metabolic bone diseases in children. Proper diet and treatment can help in prevention of rickets. Rickets is a bone disorder due to deficiency of vitamin $D$. The level of vitamin $D$ tells the severity of nutritional rickets as vitamin $D$ is the major factor of this disease. There were no undesirable side effects observed in either group of children and both oral and injectable forms of treatment were well-tolerated. Cost of oral and injectable vitamin-D was almost same.
\end{abstract}

Keywords: Vitamin D; Calcium and phosphate; Malnutrition

\section{Introduction}

Children are most sensitive to disease in the world. Proper vaccines and healthcare can help in decreasing childhood deaths in world. Malnutrition is one of the major issues around the world. According to one estimation, it is stated that one of three children daily die from malnutrition in all over the world. Malnutrition causes micronutrient and macronutrient deficiency among children. One of most prevalent micronutrient deficiency is vitamin D deficiency. Prolong Vitamin D deficiency leads to rickets in children and osteomalacia in adults.

Rickets is one of the most prevalent metabolic bone diseases in children. Proper diet and treatment can help in prevention of rickets. Rickets is a bone disorder due to deficiency of vitamin D, calcium and phosphate [1-9]. This disease causes faulty mineralization in growth plates of bones in children during childhood. Radiological and biochemical findings help in characterization of disease. Improper metabolism of calcium, vitamin D and phosphorous cause defective formation of bone in children that leads to bone abnormality and fracture [10-15]. Rickets is among the most incessant adolescence maladies in numerous developing nations. The prevalent cause is a vitamin D insufficiency, yet absence of sufficient calcium in the eating regimen may likewise prompt to rickets. In spite of the fact that it can occur in older people, the larger part of cases occurs in young children experiencing malnutrition, for the most part coming about because of starvation or starvation amid the early phases of adolescence. In developed nations, rickets is an uncommon disease (rate of under 1 in 200,000). Instances of rickets have been accounted among youngsters who are bolstered plant-based drain substitutes and not given supplemental vitamin D. It is a typical sickness in kids amid their adolescence i.e., 6 months to 3 years.

Nutritional rickets is a common health matter in numerous countries. It for the most part happens in babies who are exclusively breastfed without vitamin D supplementation. Nutritional rickets is essentially found in low wage nations in Asia, Africa, or the Middle
East exact prevalence in Pakistan is still not clear; despite the fact that its predominance in South East Asia is around 15-18\%. Because of modern lifestyle and globalization, the recurrence of nutritional rickets is rising step by step in both developed and less developed nations Carol and Frank. It has been recommended that there are diverse variables and cofactors required in the commonness of sickness e.g., distinctive dietary intake, maternal intake, natural conditions, geological circulations. In 1930's some public activities were taken and prescribed vitamin $\mathrm{D}$ and cod liver oil for new-born children and kids as a wholesome supplement. Still rickets is predominant is less developed countries Bell. In industrialized nations, rickets is more pervasive among babies and kids because of numerous reasons. Nutritional rickets is getting much consideration of wellbeing experts and clinicians around the world. It remains a far-reaching issue in many developing countries [16-20].

According to a classification, Rickets has two types i.e., Calcipenic rickets and Phosphopenic rickets. Calcipenic rickets is mainly caused by deficiency of vitamin $\mathrm{D}$, calcium or malabsorption of vitamin $\mathrm{D}$ or calcium. Phosphopenic rickets is not regular, but rather happens in exceptional circumstances like low phosphorous intake, prematurity/ total parenteral nutrition, Renal phosphate wasting, Proximal renal tubular acidosis, Fibrous dysplasia, Oncogenic hypophosphataemic rickets and Hereditary hypophosphatemia rickets Megged and Karim.

Here our primary concern is nutritional rickets, sub kind of calcipenic rickets. Wholesome rickets is a typical issue in Pakistan as highlighted in various studies. Nutritional rickets remains a common health issue in numerous nations, regardless of dramatic decreases in the predominance of the disease in numerous developed nations since the revelations of vitamin D [21-26]. Vitamin D inadequacy as well as nutritional rickets stay predominant in developing areas of the world and rank among the 5 most prevalent diseases in children. Predominance of nutritional rickets in developed nations seems, by all accounts, to be rising. Proposed reasons in the writing for its reemergence incorporate carelessness in strengthening nourishment, changing ways of life where youngsters invest a large portion of their energy inside on different types of innovation and globalization which 
Page 2 of 5

has brought about migration of various people groups to various geographic areas. Nutritional Rickets is unmistakable from different sorts of rickets in that it is just brought on by a straightforward insufficiency in vitamins and nourishment and consequently can be effectively revised if recognized early.

Primary driver of nutritional rickets is inadequacy of vitamin D. Vitamin $\mathrm{D}$ is a fat-soluble hormone imperative for calcium assimilation and bone mineralization. Its main function is maintenance of serum calcium and phosphorous level in the typical range by increasing the efficiency of the small intestine to digest these minerals from the diet. DeLuca, Reichel. Vitamin D advances calcium retention in the gut and keeps up sufficient serum calcium and phosphate levels to maintain typical mineralization of bone and to prevent hypercalcaemic tetany [27-35]. It is likewise required for bone development and bone redesigning by osteoblasts and osteoclasts. Without adequate vitamin $\mathrm{D}$, bones can turn out to be thin, weak, or misshapen. It has been concurred that serious and long lasted vitamin D lack can cause rickets in children and osteomalacia in older persons. Low level (ordinarily $<5$ $\mathrm{ng} / \mathrm{mL}$ ) of 25 -hydroxyvitamin $\mathrm{D}[25(\mathrm{OH}) \mathrm{D}]$ and disabled intestinal calcium ingestion are imperative markers of vitamin $d$ deficiency rickets.

Sunlight exposure is the major vitamin D source. Sunlight radiations vary with season and latitudes. Every country has different duration of sunlight exposure. Some countries having small duration of sunlight exposure will have less amount of vitamin D. Naturally a small number of foods contains vitamin D like oily fish (salmon, mackerel etc) fish oils or COD liver oils. According to researches, it is stated that wild salmon contains greater amount of vitamin $\mathrm{D}$ than farmed salmon. The reason is that vitamin D is abundant in food chain of wild salmon than in foods given to farmed one. Some countries have launched vitamin D fortified foods i.e., juices, yogurts, cheeses etc.

Indications of rickets can cause pain or weakness in the bone of arms, legs, pelvis or spine. It likewise causes hindered growth, short stature, bone fracture, muscle cramps, tooth disfigurements and skeletal deformities. Tooth distortions incorporates deferred tooth formation, holes in the enamel, abscesses, defects in the tooth structure and an expanded number of cavities. Skeletal deformations include a strangely moulded skull, bowlegs, or legs that bow out, bumps in the ribcage, a projecting breastbone, a bended spine, pelvic distortions [21].

Treatment of rickets varies with type of rickets. Here we will examine just nutritional rickets. The analysis of nutritional rickets is made on the premise of history, physical examination, and biochemical testing, and is affirmed by radiographs. Basic treatment of nutritional rickets is to fulfil the deficiency of vitamin $\mathrm{D}$. If there will be proper required quantity of vitamin $\mathrm{D}$ in body then there will be no chance of getting nutritional rickets [36-40]. The deficiency of vitamin $\mathrm{D}$ can be fulfilled by two ways either by supplements or by injections.

Keeping in view the severity of the issue, the present research work is designed to address the increasing incidence of vitamin D deficiency in children affected with rickets. Purposely, children with reported incidence of rickets will be administered with cholecalciferol (both oral and injectable) in the subjects for a period of 90 days. The comparison of efficiency between the oral administration and injectable doses is the limelight of the present research work.

\section{Material and Methods}

The study was conducted in Children Hospital Lahore and Fatima Memorial Hospital from May 2016 to September 2016.100 children were selected randomly. Children having age between 6 months to 3 years and having biochemical, clinical and radiological evidence of nutritional rickets were selected after taking informed consent from parents. Children having chronic disease or severe serious condition were not included. The details of each child were recorded in prescribed Performa. Clinical, biochemical and x-ray of wrist were done and their findings were recorded in Performa. The children were divided into two groups i.e., Oral (group A) and Injectable (group B). Children included in group A were given vitamin D (Cholecalciferol) i.e., 200,000 IU orally on 0 visit and children of group B were given vitamin $\mathrm{D}$ through intramuscular injection. All children were requested to come for two further follow-up visits. At each visit, the children were subjected to biochemical, clinical and radiological examination and findings were recorded.

For statistical analysis, ANOVA was used. Means were compared through LSD. Level of significance was defined as $\leq 0.05$.

\section{Results}

After data analysis, following observations were recorded at the end of study. 100 children were included in the record. 50 in group $\mathrm{A}$ (oral) and 50 in group $\mathrm{B}$ (injectable) according to prescribed inclusion criteria. $94 \%$ of children from Group A and 98\% from group B completed full study.

Basic characteristics like age, gender, weight and height are shown in Tables 1 and 2. Weight gain are statistically significant in group B and increase in height is statistically significant in group B.

\begin{tabular}{|c|c|c|c|c|}
\hline Characteristics & $\begin{array}{l}\text { Group } \\
\text { A(oral) }\end{array}$ & F-value & $\begin{array}{l}\text { Group } \\
\text { B(Injectable) }\end{array}$ & F-value \\
\hline \multicolumn{5}{|c|}{ Age (months) } \\
\hline Mean & 21.7 & & 20 & \\
\hline \multicolumn{5}{|l|}{ Gender } \\
\hline Male & 22 & & 28 & \\
\hline Female & 25 & & 21 & \\
\hline \multicolumn{5}{|c|}{ Weight (Kg) } \\
\hline Day 1 & 7.5596 & & 8.0062 & \\
\hline Day 30 & 7.9149 & 45.88 & 8.4854 & 177.12 \\
\hline Day 90 & 8.2234 & & 9.0021 & \\
\hline \multicolumn{5}{|c|}{ Height $(\mathrm{cm})$} \\
\hline Day 1 & 65.572 & & 68.406 & \\
\hline Day 30 & 72.368 & 307.81 & 72.344 & 93.85 \\
\hline Day 90 & 76.823 & & 75.371 & \\
\hline
\end{tabular}

Table 1: Basal characteristics of groups. 
Page 3 of 5

\begin{tabular}{|l|l|l|}
\hline $\begin{array}{l}\text { Signs andoms } \\
\text { symptom }\end{array}$ & Oral (Group A) & Injectable (Group B) \\
\hline Bow legs & $51.00 \%$ & $59.10 \%$ \\
\hline Frontal Bossing & $59.50 \%$ & $65.30 \%$ \\
\hline Wide wrist & $57.40 \%$ & $59.10 \%$ \\
\hline
\end{tabular}

Table 2: Signs and Symptoms.

Table 3 shows the comparison of biochemical findings between two groups. The level of Alkaline Phosphatase becomes normal in both groups but rapid improvement was seen in group $\mathrm{B}$ (injectable). The serum Calcium level increased to normal level in both levels in both groups but increase was obvious in group B as compare to group A. The level of serum Phosphorous becomes normal in both groups but rapid improvement was seen in group B than group A. The level of 25 hydroxyvitamin $\mathrm{D}$ increased to normal level in both groups but rapid increase was in group B.

\begin{tabular}{|c|c|c|c|c|}
\hline & Group A(oral) & F-value & $\begin{array}{l}\text { Group } \\
\text { B(injectable) }\end{array}$ & F-value \\
\hline & \multicolumn{2}{|l|}{ Mean \pm S.D } & \multicolumn{2}{|l|}{ Mean \pm S.D } \\
\hline \multicolumn{5}{|c|}{ I. Serum Calcium } \\
\hline Day 1 & 8.3 & & 8.0563 & \\
\hline Day 30 & 8.6 & 11.41 & 8.6687 & 69.35 \\
\hline Day 90 & 8.7 & & 8.7646 & \\
\hline \multicolumn{5}{|c|}{ II. Serum Phosphorus } \\
\hline Day 1 & 4.7 & & 4.3625 & \\
\hline Day 30 & 5.2 & 10.44 & 4.1937 & 38.03 \\
\hline Day 90 & 5.0 & & 3.4083 & \\
\hline \multicolumn{5}{|c|}{ III. Alkaline Phosphatase } \\
\hline Day 1 & 627.89 & & 668.81 & \\
\hline Day 30 & 423.43 & 324.79 & 466.17 & 829.35 \\
\hline Day 90 & 303.96 & & 251.46 & \\
\hline \multicolumn{5}{|c|}{ IV. Vitamin D } \\
\hline Day 1 & 12.7 & & 13.625 & \\
\hline Day 30 & 41.1 & 5003.73 & 56.946 & 9078.78 \\
\hline Day 90 & 58.0 & & 72.635 & \\
\hline
\end{tabular}

Table 3: Biochemical values.

Radiologically, the healing of rickets and decreasing of width in growth plate was obvious in children of injectable group. The parents preferred the injectable route over oral one there were no side effects seen in children of both groups.

\section{Discussion}

The comparison of clinical efficiency of injectable and oral form of cholecalciferol was done in this study. Children having symptoms of nutritional rickets. Each group had 50 children.

Average age in this study was $21.7 \pm 9.2$ months in group A and 20.8 \pm 8.1 months in group B. A study from Karachi included children having age between 2 months to 36 months having clinical manifestations of rickets. Nutritional rickets mostly occurs in children during age between 3 months to 18 months. A study done in Hyderabad included children having age less than 5 years. According to study done in Rawalpindi, vitamin D deficiency mostly occurs in children having age range of 9 months to 12 months. Age of rickets children range from 6 to 11 months in local study from Lahore [41-44]. According to the nutritional rickets mostly occur in children having age less than 1 year.

This study included 50\% males and $46 \%$ females. Another study included $47 \%$ males and $52 \%$ females. Mostly studies shows that there is more percentage of rickets effective males than females i.e., a study from Karachi included 62\% males and a study included 62\% males done in Peshawar. Male gender is risk factor for nutritional rickets in local study from Lahore.

Children Hospital is government hospital and covers almost treatment of poor and lower-class children at an affordable cost. The majority of population who visit this hospital is not well nourished and not aware of importance of vitamin D or sunlight. The women and children wear the local dress shalwar kameez, which covers most of the skin surfaces except face and hands.

Nutritional rickets also effects the growth of children. It is obvious from results that height and weight of affected children are not in recommended normal range in first visit and it becomes gradually normal after vitamin $\mathrm{D}$ introduction in preceding visits in both groups (injectable and oral). But obvious change was seen in injectable group as compare to oral group. Vitamin D deficiency affects the height and weight of children. Vitamin D deficiency cause improper skeletal growth in children as oddly shaped skull, bow legs, protruding abdomen etc.

Previous studies show that level of Alkaline Phosphatase increase abnormally in nutritional rickets. Results of this study also show that value of Alkaline Phosphatase is high in both groups on first visit. The decrease in Alkaline Phosphatase level after vitamin D doses was obvious in preceding visits in both groups but decrease was rapid in injectable group as compare to oral group.

Nutritional Rickets decrease the level of calcium and phosphorous as discussed in previous studies. Results of this study show that calcium and phosphorous levels were low on first day. Calcium and phosphorous becomes normal after vitamin D dosage in preceding visits. But rapid increase in Calcium and Phosphorous level was in injectable group as compare to oral group.

Vitamin D levels are biomarker of nutritional rickets. The level of vitamin $\mathrm{D}$ tells the severity of nutritional rickets as vitamin $\mathrm{D}$ is the major factor of this disease. The vitamin $\mathrm{D}$ level was low in both groups on first day. After vitamin D dosage, it increases to normal level in both groups in preceding visits.

$\mathrm{X}$-rays of wrists and knees are mostly taken for the diagnosis of nutritional rickets as mentioned in previous studies. Wrist and knee $\mathrm{x}$ rays of children were taken on every visit. The $\mathrm{x}$-ray reports showed 
improvement in healing in subsequent visits prior to first visit. There was little bit difference between the groups. Injectable group showed rapid healing as compare to oral one.

There were no undesirable side effects observed in either group of children and both oral and injectable forms of treatment were welltolerated. Cost of oral and injectable vitamin-D was almost same. Regarding route of administration of cholecalciferol, the parents preferred intramuscular route.

\section{References}

1. Abdullah MA, Salhi HS, Bakry LA, Okamoto E, Abomelha AM, et al. (2000) Adolescent Rickets in Saudi Arabia: A Rich and Sunny Country. J Pediatr Endocrinol Metab 15: 1017-1026.

2. Agarwal KS, Mughal MZ, Upadhyay P (2008) The impact of atmospheric pollution on vitamin D status of infants and toddlers in Delhi, India. Arch Dis Child 87: 111-113.

3. Ala-Houhala M, Koskinen T, Terho A (1986) Maternal compared with infant vitamin D supplementation. Arch Dis Child 61: 159-1163.

4. AL-Mustafa ZH, AL-Madan M, AL-majid HJ, AL-Muslem S, AL-Ateeq S, et al. (2007) Vitamin D deficiency and rickets in the Eastern Province of Saudi Arabia. Annals of Tropical Paediatrics 27: 63-67.

5. American Academy of Pediatrics (1999) Committee on Environmental Health. Ultraviolet light: a hazard to children. Pediatrics 104: 328-333.

6. Anatoliotaki M, Tsilimigaki A, Tsekoura T (2003) Congenital rickets due to maternal vitamin D deficiency in a sunny island of Greece. Acta Paediatr 92: 389-391.

7. Atiq M, Suria A, Nizami SQ (1998) Vitamin D status of breastfed Pakistani infants. Acta Paediatr 87: 737-740.

8. Balasubramanian K, Rajeswari J, Gulab G (2003) Varying role of vitamin $\mathrm{D}$ deficiency in the etiology of rickets in young children vs. adolescents in northern India. J Trop Pediatr 49: 201-216.

9. Baroncelli GI, Bertelloni S, Ceccarelli C (2000) Bone turnover in children with vitamin $\mathrm{D}$ deficiency rickets before and during treatment. Acta Paediatr 89: 513-518.

10. Bell DS (2011) Protean manifestations of vitamin D deficiency, part 1: the epidemic of deficiency. South Med J 104: 331-334.

11. Bhattacharyya AK (1992) Nutritional rickets in the tropics. In: Simopoulos AP (ed.) Nutrtional triggers for health and in disease, Karger, pp. 140-197.

12. Bishop N (2006) Don't ignore vitamin D. Arch. Dis. Child 91: 549-550.

13. Blok BH, Grant CC, McNeil AR, Reid IR (1998) Characteristics of children with florid vitamin $\mathrm{D}$ deficient rickets in the Auckland region in 1998. N Z Med J 113: 374-376.

14. Blumsohn A (2004) What have we learnt about the regulation of phosphate metabolism? Curr Opin Nephrol Hypertens. 13: 397-401.

15. Cannell JJ, Vieth R, Umhau JC, Holick MF, Grant WB, et al. (2006) Epidemic influenza and vitamin D.Epidemiol Infect 34: 1129-1140.

16. Chapman T, Sugar N, Done S (2010) Fractures in infants and toddlers with rickets. Pediatr Radiol 40: 1184-1189.

17. Dahifar H, Faraji A, Ghorbani A, Yassobi S (2006) Impact of dietary and lifestyle on vitamin D in healthy student girls aged 11-15 years J Med Invest 53: 204-208.

18. Das G, Crocombe S, McGrath M, Berry JL, Mughal MZ (2006) Hypovitaminosis D among healthy adolescent girls attending an inner city school. Arch. Dis. Child 91: 569-572.

19. Datta S, Alfaham M, Davies DP, Dunstan F, Woodhead S, et al. (2002) Vitamin D deficiency in pregnant women from a non-European ethnic minority population: an interventional study. Br J Obstet Gynaecol 109: 905-908.

20. Davenport ML, Uckun A, Calikoglu AS (2004) Pediatrician patterns of prescribing vitamin supplementation for infants: do they contribute to rickets? Pediatrics 113: 179-180.
21. Dawodu A, Agarwal M, Hossain M, Kochiyil J, Zayed R (2003) Hypovitaminosis D and vitamin D deficiency in exclusively breastfeeding infants and their mothers in summer: a justification for vitamin D supplementation of breast-feeding infants. J Pediatr 142: 169-173.

22. DeLucia MC, Mitnick ME, Carpenter TO (2003) Nutritional rickets with normal circulating 25-hydroxyvitamin $\mathrm{D}$ : a call for reexamining the role of dietary calcium intake in North American infants. J Clin Endocrinol Metab 88: 3539-3545.

23. Docio S, Riancho JA, Perez A, Olmos JM, Amado JA, et al. (1998) Seasonal deficiency of vitamin D in children: a potential target for osteoporosis-preventing strategies? J Bone Miner Res 13: 544-548.

24. Du X, Greenfield H, Fraser DR, Ge K, Trube A, et al. (2001) Vitamin D deficiency and associated factors in adolescent girls in Beijing. Am J Clin Nutr 74: 494-500.

25. Fischer PR, Rahman A, Cimma JP, Kyaw-Myint TO, Kabir AR, et al. (1999) Nutritional rickets without vitamin D deficiency in Bangladesh. J Trop Pediatr 45: 291-293.

26. Fischer PR, Thacher TD, Pettifor JM, Jorde LB, Eccleshall TR, et al. (2000) Vitamin D receptor polymorphisms and nutritional rickets in Nigerian children. J Bone Miner Res 15: 2206-2210.

27. Fraser DR (2004) Vitamin D deficiency in Asia. J Steroid Biochem Mol Biol 89: 491-495.

28. Fuller KE, Casparian JM (2001) Vitamin D: balancing cutaneous and systemic considerations. South Med J 94: 58-64.

29. Gannage-Yared MH, Chemali R (2000) Hypovitaminosis D in a sunny country: relation to lifestyle and bone markers. J Bone Miner Res 15: 1856-1862.

30. Gartner LM, Greer FR (2003) Prevention of rickets and vitamin D deficiency: new guidelines for vitamin D intake. Pediatrics 111: 908-910.

31. Greer FR (2003) Vitamin D deficiency: it's more than rickets. J Pediatr 143: 422-423.

32. Greer FR (2008) 25-Hydroxyvitamin D:functional outcomes in infants and young children. Am J Clin Nutr 88: 529-532.

33. Halloran BP, Bikle DD, Levens MJ (1986) Chronic 1,25dihydroxyvitaminD3 administration in the rat reduces serum concentration of 25-hydroxyvitamin $\mathrm{D}$ by increasing metabolic clearance rate. J Clin Invest 78: 622-628.

34. Halloran BP, Castro ME (1989) Vitamin D kinetics in vivo: effect of 1,25dihydroxyvitamin D administration. Am J Physiol 256: 686-691.

35. Harris NS, Crawford PB, Yangzom Y, Pinzo L, Gyaltsen P, et al. (2007) Nutritional and health status of Tibetan children living at high altitudes. N Engl J Med 344: 341-347.

36. Henderson JB, Dunnigan MG, McIntosh WB (1990) Asian osteomalacia is determined by dietary factors when exposure to ultraviolet radiation is restricted: a risk factor model. Q J Med 76: 923-933.

37. Ho ML, Yen HC, Tsang RC, Specker BL, Chen XC, et al. (1985) Randomized study of sunshine exposure and serum 25- OHD in breast fed infants in Beijing, China. J Pediatr 107: 928-931.

38. Holick MF, MacLaughlin JA, Doppelt SH (1981) Regulation of cutaneous previtamin D3 photosynthesis in man: skin pigmentation is not an essential regulator. Science 211: 590-593.

39. Hollick MF (2006) Resurrection of vitamin D deficiency and rickets. J Clin Invest 116: 2062-2072.

40. Hollis BW, Roos BA, Draper HH (1981) Vitamin D and its metabolites in human and bovine milk. J Nutr 111: 1240-1248.

41. Jesudason D, Need AG, Horowitz M, O'Loughlin PD, Morris HA, et al. (2002) Relationship between serum 25-hydroxyvitamin D and bone resorption markers in vitamin D insufficiency. Bone 31: 626-630.

42. Kreiter SR, Schwartz RP, Kirkman HN Jr (2000) Nutritional rickets in African-American breast-fed infants. J Pediatr 137: 153-157.

43. Ladhani S, Srinivasan L, Buchanan C (2004) Presentation of vitamin D deficiency. Arch Dis Child. 89: 781-784.

44. Ladizesky M, Lu Z, Oliveri B, Roman NS, Diaz S (1995) Solar ultraviolet $B$ radiation and photoproduction of vitamin D3 in central and southern areas of Argentina. J Bone Miner Res 10: 545-549. 